\title{
Review: A Safety Profile of Dalbavancin for On- and Off-Label Utilization
}

This article was published in the following Dove Press journal:

Therapeutics and Clinical Risk Management

\author{
Oriana Simonetti ${ }^{1, *}$ \\ Giulio Rizzetto $\mathbb{D}^{1, *}$ \\ Elisa Molinelli ${ }^{1}$ \\ Oscar Cirioni ${ }^{2}$ \\ Annamaria Offidani ${ }^{1}$ \\ 'Clinic of Dermatology, Department of \\ Clinical and Molecular Sciences, \\ Polytechnic University of Marche, \\ Ancona, Italy; ${ }^{2}$ Clinic of Infectious \\ Diseases, Department of Biomedical \\ Sciences and Public Health, Polytechnic \\ University of Marche, Ancona, Italy \\ *These authors contributed equally to \\ this work
}

Introduction: Dalbavancin is a bactericidal lipoglycopeptide active against gram-positives. Its use has been approved for the treatment of acute bacterial skin and skin structure infections (ABSSSI).

Methods: We conducted a narrative review of the literature on the safety profile of dalbavancin. The bibliographic research was carried out on the PubMed database on 6 November 2020 by seeking combinations of the following keywords: dalbavancin, adverse effects, safety, drug interactions, and skin infections.

Results: Five double-blind Phase 3 randomized clinical trials, 2 open-label randomized trials, and 4 retrospective studies were identified. No statistically significant differences were found between dalbavancin and comparators in the incidence of adverse events. Retrospective studies confirm the low incidence of adverse events.

Conclusion: Dalbavancin is a therapeutic option that has demonstrated an excellent safety profile, also in relation to the other MRSA therapies available. Its use represents a costeffective solution for the treatment of those patients with ABSSSI who would need hospitalization. One limitation of this study is that most of the available data are from Phase III clinical trials. Further real-life studies with a larger sample size are therefore needed to better assess the safety profile of the dalbavancin, especially to investigate the true incidence of rare adverse events.

Keywords: dalbavancin, adverse events, safety, skin infections, ABSSSI

\section{Introduction}

Dalbavancin is a bactericidal lipoglycopeptide active against gram-positives. Since May 2014, the Food and Drug Administration has approved its use for the treatment of acute bacterial skin and skin structure infections (ABSSSI) sustained by Methicillin-resistant (MRSA) and Methicillin-sensitive (MSSA) Staphylococcus aureus, Streptococcus pyogenes, Streptococcus agalactiae, Streptococcus dysgalactiae, Streptococcus anginosus, and Enterococcus faecalis (excluding vancomycinresistant VanA phenotype). ${ }^{1-4}$ ABSSSI includes cellulitis, erysipelas, traumatic and surgical wound infections, and severe cutaneous abscesses. ${ }^{5,6}$

It is reported that more than $20 \%$ of skin infections in Italy are sustained by MRSA, which represents a challenge from a therapeutic point of view. ${ }^{7,8}$ Dalbavancin is a new molecule that can play a role in overcoming antibiotic resistance, responding to the need for new drugs which are active against MRSA. Many clinical studies have demonstrated its effectiveness and excellent compliance, given its long half-life and lack of need for daily administration. ${ }^{9,10}$ A randomized phase III clinical trial ${ }^{11}$ showed that a single dose of dalbavancin $(1500 \mathrm{mg})$ is
Correspondence: Oriana Simonetti Dermatological Unit, Department of Clinical and Molecular Sciences,

Polytechnic Marche University, Via Conca 7I, Ancona, 60I26, Italy

Email o.simonetti@staff.univpm.it 
effective at 2 doses (1000 $\mathrm{mg}$ and $500 \mathrm{mg}$ after 1 week). Its efficacy has been proven to be not inferior to treatment with vancomycin and linezolid in two randomized clinical trials, DISCOVER 1 and DISCOVER $2 .{ }^{12}$

The use of dalbavancin is also economically advantageous, considering not so much the cost of the molecule, but its speed of action, the possibility of reducing hospitalization time compared to standard therapy for skin infections, the lower risk of re-hospitalization, and a faster resumption of work..$^{10,13-16}$

Dalbavancin is a semisynthetic molecule derived from a glycopeptide. ${ }^{17}$ Its mechanism of action consists in the inhibition of the transglycosylation and transpeptidation of peptidoglycans, binding to the C-terminal residues d-alanyl-d-alanine. ${ }^{18}$ Dalbavancin, therefore, prevents the formation of the cell wall and can also dimerize and anchor its lipophilic portion in bacterial membranes, increasing its antimicrobial potency compared to vancomycin. ${ }^{10,19-21}$

The pharmacokinetics of dalbavancin is linear and dosedependent, with single intravenous (iv) administration (between 140 and $1120 \mathrm{mg}$ ), showing a rapid decline after 12 hours with a slow elimination phase, which gives it a half-life of 346 hours. ${ }^{20,22,23}$ The distribution of the drug reaches adequate concentrations in skin, synovial fluid, and bone. ${ }^{24}$ In the skin, drug levels remain for up to 14 days above the minimum inhibitory concentration of $90 \%$ (MIC90) for Staphylococcus aureus (MRSA, MSSA) and $\beta$-hemolytic streptococci. ${ }^{22,24}$ Dalbavancin has no liver metabolism and is mainly eliminated by urinary excretion without modification. ${ }^{1}$ Approximately $20 \%$ of the dose administered was eliminated by fecal excretion. ${ }^{22,25}$

As numerous studies have already evaluated the efficacy of dalbavancin and its pharmacodynamic and pharmacokinetic aspects, the aim of our review is to investigate its safety profile in the treatment of skin infections, by examining and summarising the most relevant evidence from all the literature produced, considering on- and off-label use.

\section{Methods}

We conducted a narrative review of the literature on the safety profile of dalbavancin, updating it to the most recent publications. The bibliographic research was carried out on the PubMed database on 6 November 2020 by seeking combinations of the following keywords: dalbavancin, adverse effects, safety, drug interactions, and skin infections. We excluded studies that were not in English, summarizing the best evidence based on the type of study available. We first preferred the Randomized, Double-Blind, Multi-Center studies, and then considered the meta-analyzes, observational studies, case series, and case reports.

\section{Results - Safety}

Dalbavancin is a drug that has been shown to be safe and well tolerated in the two main randomized, double-blind, international, and multicentre clinical trials DISCOVER 1 and DISCOVER 2 for the treatment of skin infections. ${ }^{12}$ No cases of drug-related death have been reported. Treatment of skin infections with dalbavancin showed greater safety than treatment with vancomycin or linezolid, resulting in fewer adverse events in the two trials described by Boucher et al. ${ }^{12}$

In the literature, a pooled analysis ${ }^{26}$ was identified on two Phase II and five phase III clinical trials. ${ }^{27-32}$ Data collected on 1778 patients treated with dalbavancin and 1224 patients treated with comparators confirm the safety of the drug, reassuring that the incidence of adverse effects not yet occurring is less than $0.2 \%$. Overall, AEs were lower in the group treated with dalbavancin, 799/1778 cases, $44.9 \%$, compared to $573 / 1224$ cases, $46.8 \%$, in the group treated with comparators (cephalosporins, vancomycin, linezolid, nafcillin, and oxacillin), $\mathrm{P}=0.012$.

Patients complained of nausea, diarrhea, and pruritus, with a $2 \%$ higher incidence, while the other side effects reported were headache, constipation, vomiting, rash, insomnia, and urinary tract infection (Table 1 ). ${ }^{26}$ All these are, however, very common side effects in patients enrolled in clinical trials with antimicrobials.

Although dalbavancin has a long half-life, no late-onset adverse effects were found and there were no differences in the frequency and average duration of side effects compared to drugs with a shorter half-life. ${ }^{26}$

No significant reactions related to the infusion of the drug were reported, not even cases of red-man syndrome. However, a slow infusion of the drug for at least 30 minutes is recommended. ${ }^{12}$ No differences were identified on the safety profile based on gender, age, and race. These factors do not significantly affect the pharmacokinetics of dalbavancin and so no dose adjustment was required. ${ }^{1,10,24}$ No contraindications were reported for the administration of the drug, if not hypersensitivity to dalbavancin itself. ${ }^{1}$

In a post-marketing study ${ }^{15}$ (69 patients), the efficacy and safety of dalbavancin in both ABSSSI and osteomyelitis, endocarditis, joint prosthesis infections, and central catheter infections was evaluated. The excellent tolerability of the treatment was confirmed. Only one patient discontinued the second dose due to rectal bleeding. The most common, mainly moderate, adverse effects were rash 
(2.9\%), tachycardia $(2.9 \%)$, and nephrotoxicity $(2.9 \%)$. The latter, however, is not consistent with currently available pharmacokinetic data, especially considering the safety of dalbavancin in patients with mild to moderate renal failure. One explanation could be the concomitant poly-therapy administered to the patients in the study and their underlying pathological conditions.

Recently, Arrieta-Loitegui et $\mathrm{al}^{33}$ performed an observational retrospective analysis in 102 patients treated with dalbavancin. Of these, $69.6 \%$ (71 cases) were off-label and the most frequent were endocarditis (13.6\%) and catheterrelated bacteremia (15.7\%). Adverse effects (AEs) occurred in $3.9 \%$ of the cases (4), respectively, with hypersensitivity reaction, nausea and vomiting, skin rash, and chills related to the infusion. These are AEs which are already known and they spontaneously resolve within a short time.

As regards off-label use of the drug, studies have been conducted in clinical practice ${ }^{34-45}$ in patients with osteomyelitis, spondylodiscitis, gram-positive endocarditis, prosthetic infections, septic arthritis, and more generally in all those infections characterized by the presence of an important biofilm, confirming the effectiveness and safety of the drug. In a retrospective study ${ }^{46}$ by Morata et al on 64 patients suffering from osteoarticular infections with S. aureus and S. epidermidis, only 7 cases of AEs were observed, including 1 self-limited rash, 3 gastrointestinal problems, 1 asthenia, 1 phlebitis, and 1 case with serum creatinine increase of $0.5 \mathrm{mg} / \mathrm{dl}$. There was no need to suspend dalbavancin in any patient, underlining the safety of treatment.

Two other studies ${ }^{47,48}$ confirmed the safety of dalbavancin in endocarditis and cardiac implantable electronic device-related infections in an outpatient setting, and no adverse effects occurred. A multicenter real-life study in Austria by Wunsch et $\mathrm{al}^{49}$ conducted on 101 patients with prosthetic joint infections (31\%), osteomyelitis (29\%), endocarditis (25\%), and ABSSI (12\%) reported side effects on 3/101 patients. The first patient developed dyspnea and arterial hypertension after the second administration of dalbavancin, both of which resolved spontaneously, while the second reported fatigue after an 11-month treatment for endocarditis, and the third complained of vertigo after long-term treatment.

Finally, in a study panel, Durante-Mangoni et $\mathrm{al}^{5}$ evaluated the safety of dalbavancin in 30 patients treated for ABSSSI (8), osteomyelitis (4), prosthetic joint infection (12), catheter-related bloodstream infections (4), and infectious endocarditis (2). Three cases of AEs were reported, 1 evanescent rash for infusion and dizziness, 1 malaise, pruritus and chills, and, and 1 dyspnea and hypotension. All symptoms were moderate, and this study also confirmed the safety profile of the drug.

In clinical studies, no signs of toxicity attributable to overdose were observed, even when administering a cumulative human dose of $4500 \mathrm{mg}$ over 8 weeks. ${ }^{1}$

Below, every single aspect of the safety profile of dalbavancin is evaluated, with regard specifically to skin infections.

\section{Kidney Impairment}

Dalbavancin is a safe drug considering renal toxicity and does not require dose adjustments in mild to moderate renal insufficiency or hemodialysis patients. ${ }^{25}$ Patients with severe renal impairment (creatinine clearance $<30 \mathrm{~mL} / \mathrm{min}$ ) should receive a dose decreased by $25 \% .{ }^{1,24}$ In the study by Dunne et $a 1,{ }^{26}$ the number of patients with increased creatinine values was lower in the dalbavancin group than in the comparators group.

The pharmacokinetics of dalbavancin in subjects with end-stage renal disease undergoing regularly scheduled renal dialysis 3 times/week was similar to that observed in subjects with mild to moderate renal impairment. Less than $6 \%$ of the administered dose was removed after 3 hours of hemodialysis. ${ }^{1}$

In the animal model, renal toxicity was found at a dosage 5-7 times higher than in humans, with an increase in creatinine and blood urea nitrogen. ${ }^{1}$

\section{Liver Impairment}

The hepatic safety profile of dalbavancin is excellent and no dose adjustment is required in case of mild hepatic impairment (Child-Pugh Class A). In patients with a higher degree of hepatic insufficiency (Child-Pugh Class B or C), it should be used with caution due to lack of clinical data. ${ }^{1}$

An increased frequency of alanine aminotransferase (ALT) elevation, between 3 and 5 times the upper limit of normal (ULN), was reported in 2 phase III clinical trials $^{28}$ in patients treated with dalbavancin $(26 / 652,4 \%)$ versus vancomycin/linezolid comparators (15/651, 2.3\%).

In addition, 9 cases with ALT elevation higher than 5 times ULN was recorded in patients treated with dalbavancin and also 1 case with ALT elevation higher than 10 times ULN, in a patient with a history of hepatitis $\mathrm{C}$ and other underlying conditions. Most of these patients had a history of past liver disease and/or alcohol abuse, making these data difficult to be interpreted. ${ }^{28}$ 
In the pooled analysis, ${ }^{26}$ adverse events with elevation of transaminases were found in patients with underlying liver diseases and occurred with an incidence similar to comparators.

In the animal model, signs of hepatic toxicity were recorded after daily administration of dalbavancin for more than 28 days, with increase in serum levels of alanine aminotransferase ALT and aspartate transaminase (AST), associated with histologic findings (histiocytic vacuolation and focal hepatocyte necrosis). ${ }^{1}$

\section{Hematological Abnormalities}

No significantly different hematological abnormalities were found with the comparators. ${ }^{22}$ Only one case of asymptomatic leukopenia was recorded in the dalbavancin group (Table 2). ${ }^{22}$

A reduction in red blood cell parameters was recorded in the animal model with daily administration of dalbavancin for a period greater than 28 days. ${ }^{1}$

\section{Hypersensitivity Reactions}

Hypersensitivity reactions are rare. A single episode of transient urticaria, anaphylactoid reaction, cellulitis, and mild leukopenia was recorded, with spontaneous resolution. ${ }^{12,27,35}$

In the pooled analysis, ${ }^{26}$ there was only one case of anaphylactic reaction in a 22-year-old man with a history of atopy and asthma. The patient developed laryngospasm, dyspnea, and hypotension 15 minutes after the end of the dalbavancin infusion and had received general anesthesia 3 hours earlier.

In patients with known hypersensitivity to glycopeptides, caution is recommended in administration as episodes of cross-hypersensitivity may occur. If an allergic reaction to dalbavancin occurs, discontinuation of administration and appropriate therapy for the reaction is recommended. ${ }^{1}$

\section{Infusion-Related Reactions}

Infusion-related reactions were not significant in the pooled analysis. ${ }^{26}$ Twelve cases out of 1778 patients treated with dalbavancin were recorded compared to 53 out of 1224 with comparators. It is important to note that single administration or bi-administration after 1 week reduces the continuation of adverse events related to the infusion to a maximum of 2 days.

No cases of red man syndrome were recorded in phase III studies, although 2 cases were reported from Phase I studies. $^{26}$
To minimize the risk of infusion-related reactions, a dalbavancin infusion time of at least 30 minutes is recommended. Rapid intravenous infusions of glycopeptide antibacterial agents can cause reactions reminiscent of "Red Man Syndrome", including redness of the upper body, hives, itching, and/or skin rashes. Suspending or slowing the infusion can lead to the cessation of these reactions. ${ }^{1}$

\section{Clostridium difficile-Associated Diarrhea}

A small study ${ }^{50}$ reports that, after a single $1000 \mathrm{mg}$ dose of dalbavancin, the intestinal flora did not undergo major changes and Clostridium difficile was not isolated in the fecal material. However, the risk of developing Clostridium difficile infection was not excluded, as in most antibiotic therapies. ${ }^{1}$

Cases of Clostridium difficile-associated diarrhea (CDAD) have also been reported in patients treated with dalbavancin. ${ }^{1}$ Therefore, it is important to consider this diagnosis in patients who present with diarrhea during or after treatment, considering drug discontinuation and use of supportive measures, in association with specific treatment for C. difficile. These patients should never be treated with medicinal products that suppress peristalsis. ${ }^{1}$

No cases of antibiotic-associated colitis and pseudomembranous colitis were reported in the pooled analysis. ${ }^{26}$

\section{Dalbavancin Non-Sensitive Microorganisms}

The use of dalbavancin can promote the hyperproliferation of non-sensitive microorganisms. Attention should be paid in cases of mixed infection with Gram-positive and negative bacteria. If a superinfection occurs during therapy, appropriate measures must be taken. ${ }^{1}$

\section{Pediatric Population}

In a 2017 phase I multicenter study of 43 subjects, ${ }^{51}$ the pharmacokinetics and safety of dalbavancin in pediatric patients from 3 months to 11 years of age were investigated. The dosage was determined in relation to age as follows. From 6 years to 18 years, $12 \mathrm{mg} / \mathrm{kg}(1000 \mathrm{mg}$ maximum) and $6 \mathrm{mg} / \mathrm{kg}$ (500 $\mathrm{mg}$ maximum) after 1 week. From the age of 3 months to 6 years, $15 \mathrm{mg} / \mathrm{kg}(1000 \mathrm{mg}$ maximum) and $7.5 \mathrm{mg} / \mathrm{kg}$ (500 $\mathrm{mg}$ maximum) after 1 week. On the other hand, single-dose administration was, from the age of 6 to 18 years, $18 \mathrm{mg} / \mathrm{kg}(1500 \mathrm{mg}$ maximum), and, from the age of 3 months to 6 years, $22.5 \mathrm{mg} /$ $\mathrm{kg}$ (1500 mg maximum). 
Table I Dalbavancin Associated Adverse Events in Treatment of Skin and Skin Structure Infections

\begin{tabular}{|l|l|l|}
\hline Adverse Events (AEs) & Dalbavancin: $\mathbf{I 7 7 8}$ & Comparator: $\mathbf{I 2 2 4}$ \\
\hline TOTAL AEs (P=0.0I2) & $44.9 \%$ & $46.8 \%$ \\
Nausea & $5.5 \%$ & $6.4 \%$ \\
Headache & $4.7 \%$ & $4.8 \%$ \\
Diarrhea & $4.4 \%$ & $5.9 \%$ \\
Pruritus & $1.8 \%$ & $2.9 \%$ \\
Constipation & $2.9 \%$ & $2.5 \%$ \\
Vomiting & $2.8 \%$ & $3 \%$ \\
Rash & $2.1 \%$ & $1.8 \%$ \\
Urinary tract infection & $2 \%$ & $1.3 \%$ \\
Insomnia & $1.5 \%$ & $2.5 \%$ \\
\hline SERIOUS AEs (P=0.266) & $6.1 \%$ & $6.5 \%$ \\
Infusion-associated AEs & $2.2 \%$ & $3.1 \%$ \\
Renal-associated AEs & $1.9 \%$ & $2 \%$ \\
Hepatobiliary AEs & $1.1 \%$ & $0.7 \%$ \\
\hline
\end{tabular}

Notes: Data from Dunne et a ${ }^{26}$ (Phase 2 studies: VER00 I-4, VER00I-5; Phase 3 studies: VERO0I-8, VERO0I-9, VERO0I-I6, DISCOVER I, DISCOVER 2, see Table 3).

Table 2 Dalbavancin Associated Alterations in Laboratory Findings

\begin{tabular}{|l|l|}
\hline $\begin{array}{l}\text { Laboratory } \\
\text { Findings }\end{array}$ & Alterations Associated with Dalbavancin \\
\hline $\begin{array}{l}\text { Haematological } \\
\text { findings }\end{array}$ & $\begin{array}{l}\text { No significant differences with comparators } \\
\text { I case of asymptomatic leukopenia }\end{array}$ \\
\hline $\begin{array}{l}\text { Liver function } \\
\text { tests }\end{array}$ & $\begin{array}{l}\text { Increased frequency ALT>3-5 ULN 4\% VS 2.3\% } \\
\text { vancomycin/linezolid comparators } \\
\text { ALT-AST elevation similar to comparators }\end{array}$ \\
\hline $\begin{array}{l}\text { Kidney function } \\
\text { tests }\end{array}$ & $\begin{array}{l}\text { Fewer patients with creatinine values > I.5 ULN } \\
\text { versus comparators }\end{array}$ \\
\hline
\end{tabular}

Notes: Adapted from the pooled analysis of Dunne et $\mathrm{al}^{26}$ (Phase 2 studies: VEROOI-4, VEROOI-5; Phase 3 studies: VERO0I-8, VEROOI-9, VEROOI-16, DISCOVER I, DISCOVER 2, see Table 3).

Abbreviation: ULN, upper limit of normal.

Five cases of AEs probably related to dalbavancin treatment were recorded, such as urticaria, skin rash, asymptomatic hepatic enzyme elevation, diaper dermatitis, and infusion site discomfort. All adverse effects were moderate and resolved within a short time.

Dalbavancin has an excellent safety profile even in the pediatric population, given the absence of serious adverse effects, making it comparable to that of the adult population. ${ }^{51}$

In a previous study, ${ }^{52}$ the safety of dalbavancin was also confirmed in ten patients aged 12 to 17 years with a single dose of $1000 \mathrm{mg}$, weighing $>60 \mathrm{~kg}$, or $14 \mathrm{mg} / \mathrm{kg}$, weighing $<60 \mathrm{~kg}$. None of the adverse effects found was probably related to the drug.

\section{Ototoxicity}

Dalbavancin did not show ototoxicity in the phase I trials; ${ }^{53}$ however, patients receiving concomitant therapy with an ototoxic agent, such as an aminoglycoside, may have an increased risk. ${ }^{1}$

In the study by Wunsch et al, ${ }^{49}$ one patient suffered from vertigo after long-term therapy, which did not resolve when dalbavancin was discontinued. This is the only case reported in the literature associated with chronic mandibular osteomyelitis. No cases of ototoxicity associated with the exclusive use of dalbavancin in skin infections were detected.

\section{Effects on QT Interval}

A randomized, partially double-blind study ${ }^{54}$ on 200 people was conducted to assess the risk of prolongation of the QT interval following the intake of dalbavancin. No significant changes in heart rate or PR or QRS intervals were reported. Doses up to $1500 \mathrm{mg}$ of dalbavancin did not prolong the QTc interval and did not alter PR and QRS intervals or heart rate.

\section{Drug Interactions}

Although the available data are limited, no significant interactions with other drugs have been identified.

In an in vitro study, dalbavancin was found not to be metabolized by CYP enzymes, making it unlikely that the concomitant administration of CYP inducers or inhibitors would affect its pharmacokinetics. ${ }^{1}$

It is not yet clear whether dalbavancin is a substrate for hepatic absorption and efflux transporters. Coadministration of inhibitors of these transporters, such as protease inhibitors, verapamil, quinidine, itraconazole, clarithromycin, and cyclosporine can increase exposure to dalbavancin. It was not excluded that the administration of dalbavancin results in increased exposure to substrates of transporters, such as statins and digoxin. ${ }^{1}$

Adopting a population pharmacokinetic model based on Phase II and Phase III trial data, ${ }^{18}$ interactions with a group of medications most frequently associated with dalbavancin, such as fentanyl, acetaminophen, metronidazole, aztreonam, furosemide, simvastatin, proton-pump inhibitors, and midazolam were investigated. No interactions were identified. 
Table 3 Major Findings and Indications from Randomized Controlled Trials and Other Studies Reviewed

\begin{tabular}{|c|c|c|c|c|c|}
\hline Studies & Type of Study & $\begin{array}{l}\text { Number of } \\
\text { Patients } \\
\text { Included }\end{array}$ & Indications & Comparative Drugs & Adverse Effects (AE) \\
\hline $\begin{array}{l}\text { Boucher } \\
\text { et al }^{12} \\
\text { - DISCOVER } \\
\text { I } \\
\text { - DISCOVER } \\
2\end{array}$ & $\begin{array}{l}\text { Randomised, } \\
\text { double-blind, } \\
\text { international, and } \\
\text { multicentre } \\
\text { clinical trials } \\
\text { phase } 3\end{array}$ & $\begin{array}{l}\text { Dalbavancin (D): } \\
659 \\
\text { Vancomycin- } \\
\text { Linezolid (V-L): } \\
653 \\
\text { (both trial) }\end{array}$ & $\begin{array}{l}\text { Treatment of acute } \\
\text { bacterial skin and } \\
\text { skin-structure } \\
\text { infection* }\end{array}$ & $\begin{array}{l}\text { Dalbavancin: I g intravenously } \\
\text { (IV) on day (d) I, } 500 \mathrm{mg} \text { IV on } \\
\text { d } 8 \\
\text { Vancomycin-Linezolid: } \\
\text { vancomycin I g (or I5 mg per } \\
\text { kilogram) IV every } 12 \text { hours for at } \\
\text { least } 3 \text { days. Option to switch to } \\
\text { oral } \\
\text { linezolid } 600 \mathrm{mg} \text { every } 12 \text { hours, } \\
\text { to complete } 10 \text { to I4 days of } \\
\text { therapy }\end{array}$ & $\begin{array}{l}\text { Total events ( } \mathrm{P}=0.05 \text { ) } \\
\text { Dalbavancin: } 32.8 \% \\
\text { Vancomycine-Linezolid: } \\
37.9 \% \\
\text { Most common AE: } \\
\text { Nausea: D) } 2.5 \% \mathrm{~V}-\mathrm{L}) \\
2.9 \% \mathrm{P}=0.62 \\
\text { Diarrhea: D) } 0.8 \% \mathrm{~V}-\mathrm{L} \text { ) } \\
2.5 \% \mathrm{P}=0.02 \\
\text { Pruritus: D) } 0.6 \% \mathrm{~V}-\mathrm{L}) \\
2.3 \% \mathrm{P}=0 ., 0 \mathrm{I}\end{array}$ \\
\hline - VEROOI-8 $8^{28}$ & $\begin{array}{l}\text { Randomised, } \\
\text { double-blind trial } \\
\text { phase } 3\end{array}$ & $\begin{array}{l}\text { Dalbavancin: } \\
347 \\
\text { Cefazolin }(C): \\
186\end{array}$ & $\begin{array}{l}\text { Uncomplicated skin } \\
\text { and skin structure } \\
\text { infection }\end{array}$ & $\begin{array}{l}\text { Dalbavancin: I g IV D I } \pm 500 \mathrm{mg} \\
\text { IV D } 8 \\
\text { Cefazolin: } 500 \mathrm{mg} \text { IV every } 8 \mathrm{~h} / \\
\text { cephalexin } 500 \mathrm{mg} \text { PO QID } \times 7 \text { or } \\
\text { I4 days }\end{array}$ & $\begin{array}{l}\text { Available only aggregate } \\
\text { safety analyses of all } \\
\text { seven phase } 2 \text { and } 3 \\
\text { studies }^{26 * *}\end{array}$ \\
\hline $\begin{array}{l}\text { - VEROOI- } \\
16^{28}\end{array}$ & $\begin{array}{l}\text { Randomised, } \\
\text { double-blind trial } \\
\text { phase } 3\end{array}$ & $\begin{array}{l}\text { Dalbavancin: } \\
107 \\
\text { Vancomycin: } \\
49\end{array}$ & $\begin{array}{l}\text { Complicated skin } \\
\text { and skin structure } \\
\text { infection }\end{array}$ & $\begin{array}{l}\text { Dalbavancin: I g IV D I } \pm 500 \mathrm{mg} \\
\text { IV D } 8 \\
\text { Vancomycin } 1000 \mathrm{mg} \text { IV } \mathrm{q} \mid 2 \mathrm{~h} / \\
\text { switch based upon in vitro data } \\
\times 7 \text { or } 14 \text { days }\end{array}$ & $\begin{array}{l}\text { Available only aggregate } \\
\text { safety analyses of all } \\
\text { seven phase } 2 \text { and } 3 \\
\text { studies }^{26 * *}\end{array}$ \\
\hline - VEROOI-927 & $\begin{array}{l}\text { Randomised, } \\
\text { double-blind trial } \\
\text { phase } 3\end{array}$ & $\begin{array}{l}\text { Dalbavancin: } \\
571 \\
\text { Linezolid (L): } \\
283\end{array}$ & $\begin{array}{l}\text { Complicated skin } \\
\text { and skin structure } \\
\text { infection }\end{array}$ & $\begin{array}{l}\text { Dalbavancin: I g IV d I + } 500 \mathrm{mg} \\
\text { IV d } 8 \\
\text { Linezolid: } 600 \mathrm{mg} \text { intravenously } \\
\text { or intravenously/orally every } 12 \\
\mathrm{~h} \text { for } 14 \text { days }\end{array}$ & $\begin{array}{l}\text { Total events } \\
\text { D) } 25.4 \% \text { L) } 32.2 \% \\
\text { Most common AEs: } \\
\text { Nausea: D) } 3.2 \% \text { L) } 5.3 \% \\
\text { Diarrhea: D) } 2.5 \% \text { L) } \\
5.7 \% \\
\text { Elevated blood LDH: D) } \\
\text { I.9\% L) I.8\% } \\
\text { Headache: D) } 1.9 \% \text { L) } \\
\text { I.8\% } \\
\text { Elevated GGT: D) I.9\% } \\
\text { L) I.4\% } \\
\text { Vomiting: D) I.9\% L) } \\
\text { I.I\% } \\
\text { Rash: D) I.8\% L) I.8\% }\end{array}$ \\
\hline - VEROOI-4 & $\begin{array}{l}\text { Randomized, } \\
\text { open-label } \\
\text { phase } 2\end{array}$ & $\begin{array}{l}\text { Dalbavancin: } 40 \\
\text { DI: } 7 \text { D2: } 33 \\
\text { Vancomycin: } 34\end{array}$ & $\begin{array}{l}\text { Catheter-related } \\
\text { bloodstream } \\
\text { Infections }\end{array}$ & $\begin{array}{l}\text { Dalbavancin: DI) } 650 \mathrm{mg} \text {, then } \\
65 \mathrm{mg} \text { daily for } 7-14 \text { days D2) } \\
\text { 1000mg Day I } \pm 500 \mathrm{mg} \text { Day } 8 \\
\text { Vancomycin: } 1000 \mathrm{mg} \text { IV q12h for } \\
7-14 \text { days }\end{array}$ & $\begin{array}{l}\text { Available only aggregate } \\
\text { safety analyses of all } \\
\text { seven phase } 2 \text { and } 3 \\
\text { studies }^{26 * *}\end{array}$ \\
\hline - VEROOI-5 & $\begin{array}{l}\text { Randomized } \\
(I: I: I) \text {, open- } \\
\text { label }\end{array}$ & $\begin{array}{l}\text { Dalbavancin: } 4 \text { I } \\
\text { DI:2I D2: } 20 \\
\text { Standard of care: } \\
21\end{array}$ & $\begin{array}{l}\text { Skin and Skin } \\
\text { Structure Infection } \\
\text { (SSSI) (mixed: } \\
\text { uncomplicated and } \\
\text { complicated) }\end{array}$ & $\begin{array}{l}\text { Dalbavancin: DI) II00mg x I D2) } \\
\text { I000mg Dayl } \pm 500 \mathrm{mg} \text { Day } 8 \\
\text { Standard of care }\end{array}$ & $\begin{array}{l}\text { Available only aggregate } \\
\text { safety analyses of all } \\
\text { seven phase } 2 \text { and } 3 \\
\text { studies }^{26 * *}\end{array}$ \\
\hline
\end{tabular}

(Continued) 
Table 3 (Continued).

\begin{tabular}{|c|c|c|c|c|c|}
\hline Studies & Type of Study & $\begin{array}{l}\text { Number of } \\
\text { Patients } \\
\text { Included }\end{array}$ & Indications & Comparative Drugs & Adverse Effects (AE) \\
\hline Bouza et $\mathrm{a}^{15}$ & $\begin{array}{l}\text { Retrospective } \\
\text { study } \\
\text { (real-life) }\end{array}$ & Dalbavancin: 69 & $\begin{array}{l}\text { PJI: } 29 \% \\
\text { ABSSSI:2I.7\% } \\
\text { osteomyelitis: } 17.4 \% \\
\text { catheter related } \\
\text { Bacteraemia: } 11.6 \%\end{array}$ & $\begin{array}{l}\text { Dalbavancin: } 1500 \mathrm{mg} \text { IV, or } \\
1000 \mathrm{mg}+500 \mathrm{mg} \mathrm{IV}\end{array}$ & $\begin{array}{l}\text { Rash } 2(2.9 \%) \\
\text { Tachycardia } 2(2.9 \%) \\
\text { Impaired renal function } 2 \\
(2.9 \%) \\
\text { Nausea I (I.4\%) } \\
\text { Rectal bleeding I (I.4\%) } \\
\text { Candidiasis I (I.4\%) }\end{array}$ \\
\hline $\begin{array}{l}\text { Arrieta- } \\
\text { Loitegui } \\
\text { et } \mathrm{al}^{33}\end{array}$ & $\begin{array}{l}\text { Retrospective } \\
\text { study }\end{array}$ & Dalbavancin: 102 & $\begin{array}{l}\text { Skin and soft tissue } \\
\text { Infections: } 30.4 \% \\
\text { Catheter-related } \\
\text { Bacteraemia: } 15.7 \% \\
\text { Endocarditis: } 13.7 \% \\
\text { Bacteraemia with } \\
\text { Suspected } \\
\text { endocarditis: } 10.8 \% \\
\text { PJI: } 10.8 \% \\
\text { Osteomyelitis: } 10.8 \% \\
\text { Bacteraemia: } 4.9 \% \\
\text { Septic arthritis: } 1.9 \% \\
\text { Febrile syndrome: } \\
\text { I\% }\end{array}$ & $\begin{array}{l}\text { Dalbavancin: } 1500 \mathrm{mg} \text { IV from I } \\
\text { to } 6 \text { times every } 7 / \mathrm{I} 5 \text { days } \\
\text { Dalbavancin: } 500 \mathrm{mg} \text { IV from I to } \\
5 \text { times every } 7 \text { days }\end{array}$ & $\begin{array}{l}\text { Total AEs: } 4 \text { (3.99\%) } \\
\text { Rash: I } \\
\text { Nausea and vomiting: I } \\
\text { Infusion reaction: I } \\
\text { Hypersensitivity: I }\end{array}$ \\
\hline $\begin{array}{l}\text { Wunsch } \\
\text { et } \mathrm{al}^{49}\end{array}$ & $\begin{array}{l}\text { Multicentre, } \\
\text { retrospective } \\
\text { study }\end{array}$ & Dalbavancin: 101 & $\begin{array}{l}\text { PJI: } 31 \% \\
\text { osteomyelitis: } 29 \% \\
\text { endocarditis: } 25 \% \\
\text { ABSSSI: I } 2 \%\end{array}$ & $\begin{array}{l}\text { Dalbavancin regimen: } \\
\text { - } 1500 \mathrm{mg} \text { IV once: } 23.8 \% \\
\text { - } 1500 \mathrm{mg} \text { day (d) I + d8: } 13.9 \% \\
\text { - } 1500 \mathrm{mg} \mathrm{dI}+\mathrm{d} 8 \text { and in week } 8: \\
3 \% \\
\text { - } 1000 \mathrm{mg} \mathrm{dI} \text { followed by } 500 \mathrm{mg} \\
\text { weekly: } 42.6 \% \\
\text { - } 1000 \mathrm{mg} \text { every } 14 \mathrm{~d}: 3 \% \\
\text { - other regimens: } 13.9 \%\end{array}$ & $\begin{array}{l}\text { Total AEs: } 3 \\
\text { dyspnea and arterial } \\
\text { hypertension: I } \\
\text { severe fatigue: I (after } \\
\text { IIw treatment) } \\
\text { vertigo: I (long term } \\
\text { therapy) }\end{array}$ \\
\hline $\begin{array}{l}\text { Durante- } \\
\text { Mangoni et } \mathrm{al}^{5}\end{array}$ & $\begin{array}{l}\text { Retrospective } \\
\text { study }\end{array}$ & Dalbavancin: 30 & $\begin{array}{l}\text { ABSSSI: } 8 \\
\text { osteomyelitis: } 4 \\
\text { PJI: I2 } \\
\text { catheter-related } \\
\text { bloodstream } \\
\text { infections: } 4 \\
\text { infectious } \\
\text { endocarditis: } 2\end{array}$ & $\begin{array}{l}\text { Dalbavancin I g IV dl + } 500 \mathrm{mg} \\
\text { Day } 8\end{array}$ & $\begin{array}{l}\text { Total AEs: } 3 \text { cases (all } \\
\text { moderate) } \\
\text { evanescent rash } \\
\text { (infusion), dizziness: I } \\
\text { malaise, pruritus and } \\
\text { chills: I dyspnea and } \\
\text { hypotension: I }\end{array}$ \\
\hline
\end{tabular}

Notes: *Skin-structure infection required the presence of cellulitis, a major abscess, or a wound infection, each associated with at least $75 \mathrm{~cm} 2$ of erythema. $* *$ Phase 2 studies: VEROOI-4, VEROOI-5; Phase 3 studies: VERO0I-8, VERO0I-9, VER00I-I6, DISCOVER I, DISCOVER 2.

Abbreviations: ABSSSI, acute bacterial skin and skin-structure infection; PJI, prosthetic joint infection; LDH, lactate dehydrogenase level; GGT, g-glutamyltransferase.

\section{Pregnancy, Lactation, Fertility}

There are no clear data on the use of dalbavancin in pregnant women. Currently, the drug falls into pregnancy class C. ${ }^{55,56}$ We found in the literature only one case report $^{57}$ of dalbavancin therapeutic failure in a pregnant woman with bacterial endocarditis. There were no side effects attributable to the drug. However, it has been hypothesized that the increase in the glomerular filtration rate and the reduction in serum albumin in pregnancy may have reduced the drug's half-life. Further studies are 
needed to investigate the safety and efficacy of dalbavancin in pregnancy. For this reason, dalbavancin is not recommended during pregnancy unless strictly necessary. ${ }^{1}$

It is not known whether dalbavancin is excreted in human milk. However, the evidence that dalbavancin is excreted in the milk of lactating rats may also indicate a possible presence of the drug in human breast milk. Even considering that dalbavancin is not well absorbed orally, an impact on the gastrointestinal and oral flora of a breastfed infant cannot be excluded. In this case, it is necessary to carefully evaluate the risk/benefit of administering the drug. ${ }^{1}$

Animal studies have shown reduced fertility and reproductive toxicity. The potential risk for humans is not known. ${ }^{1}$

\section{Animal Model}

The animal model allowed to evaluate the toxicity of dalbavancin in rats and dogs after daily intravenous administration for up to 3 months. Dose-dependent reactions related to the infusion were observed only in dogs, and they resolved after 1 hour from administration, and were attributable to the release of histamine. These included swelling and/or redness of the skin, pale mucous membranes, salivation, vomiting, sedation, modest drops in blood pressure, and increased heart rate. ${ }^{1}$

In rats, when exposure was approximately 3 times that of human clinical exposure, there was a reduction in fertility and an increased incidence of lethality to embryos, reduction in fetal weight, skeletal ossification, and increased neonatal mortality. In rabbits, abortion was associated with maternal toxicity following exposure below the therapeutic range used in humans. ${ }^{1}$

Long-term carcinogenicity studies have not been conducted. In a series of in vitro and in vivo genotoxicity tests, dalbavancin was neither mutagenic nor clastogenic. ${ }^{1}$

Furthermore, a recent study ${ }^{58}$ showed that dalbavancin treatment of MRSA-infected wounds in mice not only resolved the infection but also promoted a better tissue repair setting than vancomycin treatment, with increased epidermal growth factor receptor (EGFR) and vascular endothelial growth factor (VEGF).

\section{Conclusions}

Dalbavancin is a therapeutic option that has demonstrated an excellent safety profile, also compared to the other MRSA therapies available. Its use represents a costeffective solution for the treatment of patients with ABSSSI who would require hospitalization, as a single outpatient dose of dalbavancin can reduce days of hospitalization and allows patients to return to their activities more quickly. ${ }^{32,59}$ Savings of approximately $€ 3477.78$ per patient are estimated considering the reduction in hospitalization compared to standard vancomycin therapy, as reported in a study of 102 patients in Spain. ${ }^{33}$ This is possible thanks to the pharmacodynamics and pharmacokinetics of dalbavancin, which differs from that of other glycopeptides.

Some limitations on the data in the literature concern the safety and efficacy of dalbavancin when administered for more than two doses. There is also no experience with dalbavancin in the treatment of patients with severe immunosuppression and obesity.

It is important to note that most of the available data are from phase III clinical trials. Further real-life studies with a larger sample size are therefore needed to better assess the safety profile of the dalbavancin, especially to investigate the true incidence of rare adverse events.

\section{Disclosure}

The authors report no conflicts of interest in this work.

\section{References}

1. Dalvance prescribing information. Available from: http://www.access data.fda.gov/drugsatfda_docs/label/2014/021883s000lblpdf. Accessed November 10, 2020.

2. Lin G, Credito K, Ednie LM, Appelbaum PC. Antistaphylococcal activity of dalbavancin, an experimental glycopeptides. Antimicrob Agents Chemother. 2005;49(2):770-772. doi:10.1128/AAC.49.2.770772.2005

3. Pfaller MA, Flamm RK, Castanheira M, Sader HS, Mendes RE. Dalbavancin in-vitro activity obtained against Gram-positive clinical isolates causing bone and joint infections in US and European hospitals (2011-2016). Int $J$ Antimicrob Agents. 2018;51:608-611. doi:10.1016/j.jjantimicag.2017.12.011

4. Smith JR, Roberts KD, Rybak MJ. Dalbavancin: a novel lipoglycopeptide antibiotic with extended activity against Gram-positive infections. Infect Dis Ther. 2015;4:245-258. doi:10.1007/s40121-015-0077-7

5. Durante-Mangoni E, Gambardella M, Iula VD, et al. Current trends in the real-life use of dalbavancin: report of a study panel. Int $J$ Antimicrob Agents. 2020;56(4):106107. doi:10.1016/j. ijantimicag.2020.106107

6. Esposito S, Noviello S, Leone S. Dalbavancin for the treatment of acute bacterial skin and skin structure infections. Infez Med. 2015;23 (4):313-317.

7. European Centre for Disease Prevention and Control. Antimicrobial resistance surveillance in Europe 2018. Annual report of the European Antimicrobial Resistance Surveillance Network (EARS-Net). Available from: https://www.ecdc.europa.eu/sites/default/files/docu ments/surveillance-antimicrobial-resistance-Europe-2018.pdf. Accessed March 9, 2021.

8. Bassetti M, Carnelutti A, Castaldo N, Peghin M. Important new therapies for methicillin-resistant Staphylococcus aureus. Expert Opin Pharmacother. 2019;20(18):2317-2334. doi:10.1080/14656566. 2019.1675637 
9. Zhanel GG, Calic D, Schweizer F, et al. New lipoglycopeptides: a comparative review of dalbavancin, oritavancin and telavancin. Drugs. 2010;70:859-886. doi:10.2165/11534440-000000000-00000

10. Leuthner KD, Buechler KA, Kogan D, Saguros A, Lee HS. Clinical efficacy of dalbavancin for the treatment of acute bacterial skin and skin structure infections (ABSSSI). Ther Clin Risk Manag. 2016;12:931-940. doi:10.2147/TCRM.S86330

11. Dunne MW, Puttagunta S, Giordano P, Krievins D, Zelasky M, Baldassarre J. A randomized clinical trial of single-dose versus weekly dalbavancin for treatment of acute bacterial skin and skin structure infection. Clin Infect Dis. 2016;62(5):545-551. doi:10.1093/ cid/civ982

12. Boucher HW, Wilcox M, Talbot GH, Puttagunta S, Das AF, Dunne MW. Once-weekly dalbavancin versus daily conventional therapy for skin infection. $N$ Engl J Med. 2014;370(23):2169-2179. doi:10.1056/NEJMoa1310480

13. Agarwal R, Bartsch SM, Kelly BJ, et al. Newer glycopeptide antibiotics for treatment of complicated skin and soft tissue infections: systematic review, network meta-analysis and cost analysis. Clin Microbiol Infect. 2018;24(4):361-368. doi:10.1016/j. cmi.2017.08.028

14. Klinker KP, Borgert SJ. Beyond vancomycin: the tail of the lipoglycopeptides. Clin Ther. 2015;37(12):2619-2636. doi:10.1016/ j.clinthera.2015.11.007

15. Bouza E, Valerio M, Soriano A, et al. Dalbavancin in the treatment of different gram-positive infections: a real-life experience. Int $J$ Antimicrob Agents. 2018;51(4):571-577. doi:10.1016/j. ijantimicag.2017.11.008

16. Juul JJ, Mullins CF, Peppard WJ, Huang AM. New developments in the treatment of acute bacterial skin and skin structure infections: considerations for the effective use of dalbavancin. Ther Clin Risk Manag. 2016;12:225-232. doi:10.2147/TCRM.S71855

17. Sosio M, Stinchi S, Beltrametti F, Lazzarini A, Donadio S. The gene cluster for the biosynthesis of the glycopeptide antibiotic A40926 by Nonomuraea species. Chem Biol. 2003;10(6):541-549. doi:10.1016/ S1074-5521(03)00120-0

18. Ciabatti R. Semisynthetic glycopeptides: chemistry, structure-activity relationships and prospects. Farmaco. 1997;52:313-321.

19. Streit JM, Fritsche TR, Sader HS, et al. Worldwide assessment of dalbavancin activity and spectrum against over 6000 clinical isolates Diagn Microbiol Infect Dis. 2004;48:137-143. doi:10.1016/j. diagmicrobio.2003.09.004

20. Bailey J, Summers KM. Dalbavancin: a new lipoglycopeptide antibiotic. Am J Health Syst Pharm. 2008;65:599. doi:10.2146/ ajhp070255

21. Chen AY, Zervos MJ, Vazquez JA. Dalbavancin: a novel antimicrobial. Int J Clin Pract. 2007;61(5):853-863. doi:10.1111/ j.1742-1241.2007.01318.x

22. Buckwalter M, Dowell JA. Population pharmacokinetic analysis of dalbavancin, a novel lipoglycopeptide. J Clin Pharmacol. 2005;45 (11):1279-1287. doi:10.1177/0091270005280378

23. Leighton A, Gottlieb AB, Dorr MB, et al. Tolerability, pharmacokinetics, and serum bactericidal activity of intravenous dalbavancin in healthy volunteers. Antimicrob Agents Chemother. 2004;48:940-945. doi:10.1128/AAC.48.3.940-945.2004

24. Marbury T, Dowell JA, Seltzer E, Buckwalter M. Pharmacokinetics of dalbavancin in patients with renal or hepatic impairment. J Clin Pharmacol. 2009;49:465-476. doi:10.1177/0091270008330162

25. Stogniew M, Pu F, Dowell JA, Henkel T. Pharmacokinetic attributes of dalbavancin: well distributed and completely eliminated with dual routes of elimination. Clin Microbiol Infect. 2003;9(suppl 1):291.

26. Dunne MW, Talbot GH, Boucher HW, Wileox M, Puttagunta S. Safety of dalbavancin in the treatment of skin and skin structure infections: a pooled analysis of randomized comparative studies. Drug Saf. 2016;39(2):147-157. doi:10.1007/s40264-015-0374-9
27. Jauregui LE, Babazadeh S, Seltzer E, et al. Randomized, double-blind comparison of once-weekly versus twice-daily linezolid therapy for the treatment of complicated skin and skin structure infections. Clin Infect Dis. 2005;41(10):1407-1415. doi:10.1086/497271

28. Dalbavancin for injection for treatment of acute bacterial skin and skin structure infections. NDA 021-883 briefing document. Presented to the FDA Anti-Infective Drugs Advisory Committee 31 March 2014. Available from: http://www.fda.gov/downloads/ AdvisoryCommittees/CommitteesMeetingMaterials/Drugs/AntiInfectiveDrugsAdvisoryCommittee/UCM390793.pdf. Accessed October 2020

29. Seltzer E, Dorr MB, Goldstein BP, et al. Once-weekly dalbavancin versus standard-of-care antimicrobial regimens for treatment of skin and soft-tissue infections. Clin Infect Dis. 2003;37(10):1298-1303. doi: $10.1086 / 379015$

30. Raad I, Darouiche R, Vazquez J, et al. Efficacy and safety of weekly dalbavancin therapy for catheter-related bloodstream infection caused by gram-positive pathogens. Clin Infect Dis. 2005;40(3):374-380. doi: $10.1086 / 427283$

31. Petrakis V, Panagopoulos P, Papanas N. Dalbavancin for the treatment of complicated gram-positive skin and soft tissue infections. Int J Low Extrem Wounds. 2020;19(3):236-241. doi:10.1177/ 1534734620921677

32. Laupland KB, Valiquette L. Outpatient parenteral antimicrobial therapy. Can J Infect Dis Med Microbiol. 2013;24(1):9-11. doi:10.1155/2013/205910

33. Arrieta-Loitegui M, Caro-Teller JM, Ortiz-Pérez S, et al. Effectiveness, safety and cost analysis of dalbavancin in clinical practice. Eur J Hosp Pharm. 2020. doi:10.1136/ejhpharm-2020002315

34. Solon EG, Dowell JA, Lee J, King SP, Damle BD. Distribution of radioactivity in bone and related structures following administration of [14 C]dalbavancin to New Zealand white rabbits. Antimicrob Agents Chemother. 2007;51(8):3008-3010. doi:10.1128/ AAC.00020-07

35. Dunne MW, Puttagunta S, Sprenger CR, et al. Extended-duration dosing and distribution of dalbavancin into bone and articular tissue. Antimicrob Agents Chemother. 2015;59(4):1849-1855. doi:10.1128/AAC.04550-14

36. Rappo U, Puttagunta S, Shevchenko V, et al. Dalbavancin for the treatment of osteomyelitis in adult patients: a randomized clinical trial of efficacy and safety. Open Forum Infect Dis. 2019;6:ofy331. doi:10.1093/ofid/ofy331

37. Almangour TA, Fletcher V, Alessa M, Alhifany AA, Tabb D. Multiple Weekly dalbavancin dosing for the treatment of native vertebral osteomyelitis caused by methicillin-resistant Staphylococcus aureus: a case report. Am J Case Rep. 2017;18:1315-1319. doi:10.12659/AJCR.905930

38. Mavrogenis AF, Megaloikonomos PD, Igoumenou VG, et al. Spondylodiscitis revisited. EFORT Open Rev. 2017;2:447-461. doi:10.1302/2058-5241.2.160062

39. Sur A, Tsang K, Brown M, Tzerakis N. Management of adult spontaneous spondylodiscitis and its rising incidence. Ann $R$ Coll Surg Engl. 2015;97:451-455. doi:10.1308/rcsann.2015.0009

40. Buzón Martín L, Mora Fernández M, Perales Ruiz JM, et al. Dalbavancin for treating prosthetic joint infections caused by Gram-positive bacteria: a proposal for a low dose strategy. A retrospective cohort study. Rev Esp Quimioter. 2019;32(6):532-538.

41. Ajaka L, Heil E, Schmalzle S. Dalbavancin in the treatment of bacteremia and endocarditis in people with barriers to standard care. Antibiotics (Basel). 2020;9(10):700. doi:10.3390/ antibiotics9100700

42. Bork JT, Heil EL, Berry S, et al. Dalbavancin use in vulnerable patients receiving outpatient parenteral antibiotic therapy for invasive gram-positive infections. Infect Dis Ther. 2019;8(2):171-184. doi:10.1007/s40121-019-0247-0 
43. Hakim A, Braun H, Thornton D, Strymish J. Successful treatment of methicillin-sensitive Staphylococcus aureus tricuspid-valve endocarditis with dalbavancin as an outpatient in a person who injects drugs: a case report. Int $J$ Infect Dis. 2020;91:202-205. doi:10.1016/j. ijid.2019.12.008

44. Barnea Y, Lerner A, Aizic A, et al. Efficacy of dalbavancin in the treatment of MRSA rat sternal osteomyelitis with mediastinitis. $J$ Antimicrob Chemother. 2016;71(2):460-463. doi:10.1093/jac/ dkv357

45. Dinh A, Duran C, Pavese P, et al.; Dalbavancin French Study Group. French national cohort of first use of dalbavancin: a high proportion of off-label use. Int J Antimicrob Agents. 2019;54(5):668-672.

46. Morata L, Cobo J, Fernández-Sampedro M, et al. Safety and efficacy of prolonged use of dalbavancin in bone and joint infections. Antimicrob Agents Chemother. 2019;63:e2280-18. doi:10.1128/ AAC.02280-18

47. Tobudic S, Forstner C, Burgmann H, et al. Dalbavancin as primary and sequential treatment for Gram-positive infective endocarditis: 2-year experience at the General Hospital of Vienna. Clin Infect Dis. 2018;67:795-798.

48. Jones RN, Farrell DJ, Flamm RK, Sader HS, Dunne MW, Mendes RE. Surrogate analysis of vancomycin to predict susceptible categorization of dalbavancin. Diagn Microbiol Infect Dis. 2015;82:73-77. doi:10.1016/j.diagmicrobio.2015.01.017

49. Wunsch S, Krause R, Valentin T, et al. Multicenter clinical experience of real life dalbavancin use in Gram-positive infections. Int J Infect Dis. 2019;81:210-214. doi:10.1016/j.ijid.2019.02.013

50. Nord CE, Rasmanis G, Wahlund E. Effect of dalbavancin on the normal intestinal microflora. J Antimicrob Chemother. 2006;58 (3):627-631. doi:10.1093/jac/dk1281

51. Gonzalez D, Bradley JS, Blumer J, et al. Dalbavancin pharmacokinetics and safety in children 3 months to 11 years of age. Pediatr Infect Dis J. 2017;36(7):645-653.
52. Bradley J, Puttagunta S, Rubino C, Blumer J, Dunne M, Sullivan J. Pharmacokinetics, safety and tolerability of single dose dalbavancin in children 12 through 17 years of age. Pediatr Infect Dis J. 2015;34 (7):748-752. doi:10.1097/INF.0000000000000646

53. Campbell K, Kelly E, Targovnik N, et al. Audiologic monitoring for potential ototoxicity in a phase I clinical trial of a new glycopeptide. $J$ Am Acad Audiol. 2003;14(3):157-168. doi:10.1055/s-00401715720

54. Dunne MW, Zhou M, Borje Darpo B. A thorough QT study with dalbavancin: a novel lipoglycopeptide antibiotic for the treatment of acute bacterial skin and skin-structure infections. Int J Antimicrob Agents. 2015;45(4):393-398. doi:10.1016/j.ijantimicag.2014.12.021

55. Dowell JA, Goldstein BP, Buckwalter M, et al. Pharmacokineticpharmacodynamic modeling of dalbavancin, a novel glycopeptide antibiotic. J Clin Pharmacol. 2008;48:1063-1068. doi:10.1177/ 0091270008321273

56. Bookstaver PB, Bland CM, Griffin B, Stover KR, Eiland LS, McLaughlin M. A review of antibiotic use in pregnancy. Pharmacotherapy. 2015;35(11):1052-1062. doi:10.1002/phar.1649

57. Steele JM, Seabury RW, Hale CM, Mogle BT. Unsuccessful treatment of methicillin-resistant Staphylococcus aureus endocarditis with dalbavancin. J Clin Pharm Ther. 2018;43(1):101-103. doi:10.1111/ jcpt. 12580

58. Simonetti O, Lucarini G, Morroni G, et al. New evidence and insights on dalbavancin and wound healing in a mouse model of skin infection. Antimicrob Agents Chemother. 2020;64(4):e02062-19. doi:10.1128/AAC.02062-19

59. Barr DA, Seaton RA. Outpatient parenteral antimicrobial therapy (OPAT) and the general physician. Clin Med (Lond). 2013;13 (5):495-499. doi:10.7861/clinmedicine.13-5-495
Therapeutics and Clinical Risk Management

\section{Publish your work in this journal}

Therapeutics and Clinical Risk Management is an international, peerreviewed journal of clinical therapeutics and risk management, focusing on concise rapid reporting of clinical studies in all therapeutic areas, outcomes, safety, and programs for the effective, safe, and sustained use of medicines. This journal is indexed on PubMed Central, CAS,

\section{Dovepress}

EMBase, Scopus and the Elsevier Bibliographic databases. The manuscript management system is completely online and includes a very quick and fair peer-review system, which is all easy to use. Visit http://www.dovepress.com/testimonials.php to read real quotes from published authors. 